\title{
Inflammation with HTLV-1-specific CTLs occurs in the spinal cord of HTLV-1 carriers and the brain of the patients with HAM/TSP
}

\author{
Eiji Matsuura ${ }^{1 *}$, Satoshi Nozuma1', Toshio Matsuzaki ${ }^{2}$, Osamu Watanabe ${ }^{1}$, Ryuji Kubota$^{2}$, Shuji Izumo², \\ Hiroshi Takashima'
}

From 16th International Conference on Human Retroviruses: HTLV and Related Viruses

Montreal, Canada. 26-30 June 2013

Recently, a study by Morgan et al. identified that the white matter lesions are detectable with MRI study in HTLV-1 carriers at the same frequency as HAM/TSP patients. Little is known about the nature of the brain lesion and its relation to the spinal cord lesion. We assessed the inflammatory change including HTLV-1-specific cytotoxic T lymphocytes in the brain lesion of the patient with HAM/ TSP, in the spinal cord of HTLV-1 carrier immunohistochemically. Fresh frozen samples including one brain from the patient with HAM/TSP and four spinal cords from HTLV-1 carriers were for use in this study. Inflammatory cells in the sections of the brain and spinal cords were stained with anti-CD4, anti-CD8 antibodies. HTLV-1specific CTLs were detected with either phycoerythrin (PE)-conjugated HLA-A*0201/Tax11-19 tetramer or HLA-A $2402 /$ Tax301-309 tetramer, and followed by rabbit anti-PE antibody as the secondary antibody. The signals from the third antibody with fluorescence were captured by confocal laser scanning microscopy (CLSM). HTLV-1specific CTLs were frequently detected in the brain lesion of the patient with HAM/TSP. The CTLs were also detected in all the spinal cords of four HTLV-1 carriers. Interestingly, inflamed lesions of HTLV-1 carrier were distributed mainly in the lower thoracic level of the spinal cords like the spinal cord of HAM/TSP. These results suggest that inflammatory changes occur simultaneously in the spinal cord and the brain of the patients with $\mathrm{HAM} / \mathrm{TSP}$, and that latent inflammatory change may occur in asymptomatic HTLV-1 carriers.

\footnotetext{
* Correspondence: pine@m.kufm.kagoshima-u.ac.jp 'Department of Neurology and Geriatrics, Kagoshima University Graduate School of Medical and Dental Sciences, Kagoshima, Japan Full list of author information is available at the end of the article
}

\section{Authors' details}

'Department of Neurology and Geriatrics, Kagoshima University Graduate School of Medical and Dental Sciences, Kagoshima, Japan. ${ }^{2}$ Department of Molecular Pathology, Center for Chronic Viral Diseases, Kagoshima University, Kagoshima, Japan.

Published: 7 January 2014

doi:10.1186/1742-4690-11-S1-P7

Cite this article as: Matsuura et al:: Inflammation with HTLV-1-specific CTLs occurs in the spinal cord of HTLV-1 carriers and the brain of the patients with HAM/TSP. Retrovirology 2014 11(Suppl 1):P7.

Submit your next manuscript to BioMed Central and take full advantage of:

- Convenient online submission

- Thorough peer review

- No space constraints or color figure charges

- Immediate publication on acceptance

- Inclusion in PubMed, CAS, Scopus and Google Scholar

- Research which is freely available for redistribution

Submit your manuscript at www.biomedcentral.com/submit
() Biomed Central 